\title{
AVALIAÇÃO DA PERDA DA VEGETAÇÃO ARBÓREA NATIVA NA SERRA DA BODOQUENA, MATO GROSSO DO SUL, POR MEIO DE SENSORIAMENTO REMOTO
}

\section{Evaluation of the loss of the native arboreous vegetation in the Mountain Range of Bodoquena, Mato Grosso do Sul State, by means of remote sensing}

\author{
Ademir Kleber Morbeck de OLIVEIRA ${ }^{1}$ \\ Valtecir FERNANDES ${ }^{2}$ \\ Silvio Jacks dos Anjos GARNÉS ${ }^{3}$ \\ Celso Ramão Bernardes dos SANTOS ${ }^{4}$
}

\begin{abstract}
RESUMO
Este trabalho avalia as modificações ocorridas na vegetação arbórea nativa da Serra da Bodoquena, Mato Grosso do Sul, no período entre 1966 e 2007, através de imagens de sensoriamento remoto. Foi obtida uma sequência de imagens temporais que permitiram avaliar os tipos de vegetação predominante, sua extensão e como a ação antrópica na região está alterando este maciço florestal. Os resultados indicam que a região é coberta predominantemente por Cerrado Lato sensu e Florestas, Decidual Submontana e Semidecidual, cobrindo em 1966, 1799.091,63 ha e em 2007, 1693.797,40 ha. Durante o período avaliado, a região perdeu $10,19 \%$ de sua cobertura vegetal, substituída por áreas de pastagens e culturas agrícolas.
\end{abstract}

Palavras-chave: Imagens de satélite; Geoprocessamento; Espaço geográfico; Análise ambiental.

\begin{abstract}
This work evaluates the modifications occurred in the native vegetation in the Mountain Range of Bodoquena, Mato Grosso do Sul State, in the period between 1966 and 2007, through images of remote sensing. An amount of time series images were obtained and they allowed the evaluation of the kinds of predominant vegetation, its size and effects over the antropic action in the region which has been causing changes to this big forest. The results indicate that the region is covered predominantly by Cerrado Latu Sensu and Forests, Decidual Submontana and Semidecidual, covering in 1966, 1799.091,63 ha and in 2007, 1693.797,40 ha. During the period evaluated, lost $10.19 \%$ of its vegetal cover, replaced by areas of pastures and agricultural cultures.
\end{abstract}

Keywords: Images of satellite; Geoprocessing; Geographical landscape; Environmental analysis.

1 Biólogo e doutor em Ciências pela Universidade Federal de São Carlos - UFSCar. Professor do Programa de Pós-Graduação em Meio Ambiente e Desenvolvimento Regional da Universidade para o Desenvolvimento do Estado e da Região do Pantanal (UNIDERP). E-mail: akmorbeck@hotmail.com

2 Biólogo e mestre em Meio Ambiente e Desenvolvimento Regional pela Universidade para o Desenvolvimento do Estado e da Região do Pantanal (UNIDERP). Bolsista Fundect. E-mail: biovfernandes@yahoo.com.br.

3 Engenheiro agrimensor e doutor em Ciências Geodésicas pela Universidade Federal do Paraná - UFPr. Professor do Programa de Pós-Graduação em Meio Ambiente e Desenvolvimento Regional da Universidade para o Desenvolvimento do Estado e da Região do Pantanal (UNIDERP). E-mail: sjgarnes@yahoo.com.br.

4 Engenheiro agrimensor pela Universidade para o Desenvolvimento do Estado e da Região do Pantanal - UNIDERP. Técnico do Laboratório de Geoprocessamento (UNIDERP). E-mail: netcelso@yahoo.com.br. 


\section{INTRODUÇÃO}

As imagens de satélites aliadas as técnicas de processamento digital são ferramentas importantes para identificação da cobertura vegetal do solo em uma determinada região. Por meio das comparações e classificações das temáticas de diferentes períodos, é possível entender a dinâmica de ocupação e da estrutura da paisagem, a fim de servir como base para subsidiar políticas de conservação, tornando-se uma eficiente ferramenta que permite avaliar o grau de alteração que os ecossistemas apresentam, principalmente aqueles de relevante interesse ambiental (SALLES et al, 2005).

A tecnologia desenvolvida em sensoriamento remoto tem um papel importante em Ecologia de Paisagem e, por conseguinte, no monitoramento das alterações provocadas em áreas naturais, permitindo identificações mais precisas dos diferentes tipos de vegetações, o que pode possibilitar ações de interesse acadêmico, subsídios para elaboração de planos de manejo, delineamento de habitats disponíveis para fauna, identificação de remanescentes de vegetação fora de áreas legalmente protegidas ou para o planejamento ambiental em uma escala que abarque bacias hidrográficas ou outras unidades da paisagem (LIU, 2007).

A aplicação das técnicas de sensoriamento remoto no estudo da vegetação inclui a necessidade de compreender o processo de interação entre a REM (Radiação Eletromagnética) e todas as partes que compõem uma planta, o que subentende o estudo dessa interação com os diversos tipos fisionômicos (florestas, culturas agrícolas, formações de porte herbáceo) uma vez que a folha é o principal elemento da vegetação sob o ponto de vista do processo de interação com o REM (PONZONI, 2001).

Aplicar a técnica REM em remanescentes vegetais submetidos a pressão antrópica, em áreas de interesse conservacionista, como a Serra da Bodoquena, Estado de Mato Grosso do Sul, uma das poucas regiões que apresenta cobertura florestal ainda parcialmente preservada, com feições de relevo associadas ao desenvolvimento geomorfológico sobre terreno calcário denominado carste (BOGGIANI, 1999), é um importante elemento nos processos de preservação destes ambientes.

Esta área é a mais importante feição geomorfológica regional, não só pela altitude que se eleva 300 a 600 metros, dentro do quadro de planícies do Estado, como por ser um extenso divisor entre a bacia do rio Paraguai a Oeste e as sub-bacias do rio Apa ao Sul e Miranda a Leste, estendendo-se sem interrupção ao longo de mais de $220 \mathrm{~km}$ no sentido norte sul, onde nasce parte dos rios que deságuam no Pantanal, como os rio Salobra, Formoso, Peixe, Perdido, Caracol e Aquidabã, além da região também ser importante para a recarga do Aquífero Guarani, um das maiores reservas subterrâneas de água do País (ALVARENGA et al., 1982; BATARCE; MORETTI, 2006).

No Estado, as maiores perdas de vegetação arbórea foram detectadas na região centro-sul, onde se situam áreas com vegetação classificada como Floresta Estacional (Serra da Bodoquena), que apresentam maior potencialidade de uso racional do potencial madeireiro e permitem a instalação de Planos de Manejo Florestal, condizente com as necessidades de fornecimento de madeira para suprir o mercado local e nacional. A vegetação existente nessa região, de acordo com alguns autores, é classificada como área de domínio da Mata Atlântica, abrangendo inicialmente $17,54 \%$ da área total do Estado e atualmente reduzida a apenas 0,56\% (SCHAEFFER et al., 2005).

Apesar de o Código Florestal Brasileiro datar de 1965, somente houve preocupação na preservação dos recursos florestais transcorridos 20 anos de sua publicação. Nesse intervalo, o desmatamento de áreas florestais ocorreu sem critérios técnicos e preservacionistas (SCHAEFFER et al., 2005).

A vegetação de porte arbóreo ainda existente na região da Serra da Bodoquena situa-se nas porções mais elevadas, formado um grande maciço florestal, conservado principalmente pelo fato de estar sobre um relevo acidentado, o que acaba por dificultar o uso para outros fins (DIAS, 2000). As fitofisionomias mais típicas são as chamadas matas secas, associadas às rochas calcárias; ocorrem também na região Floresta Estacional Decidual Submontana, Savana Florestada, Cerrado lato sensu, Floresta Estacional Semidecidual Aluvial (Formações Ripárias) além das florestas "Matas de palo-blanco", que fazem parte das matas de transição do Chaco da Argentina (FURTADO et al., 1982; BRASIL, 1997; POTT; POTT, 2003).

A vegetação varia conforme o relevo e tipo de solo. Nas áreas planas do Planalto, o solo é de Terra Roxa Estruturada, onde se desenvolve a vegetação de Cerrado com suas variações fisionômicas e estruturais: cerradão, campo cerrado e campo limpo. Onde ocorre exposição de rochas carbonáticas, o solo é pouco desenvolvido e a vegetação é de Floresta Estacional Semidecidual de Terras Baixas e Floresta Estacional Decidual Submontana (FURTADO et al., 1982; DAMASCENO-JÚNIOR et al., 2000).

Entre estas formações, a Floresta Estacional Decidual Submontana caracteriza-se por apresentar mais de $60 \%$ das plantas com perdas de folhagem 
durante a época desfavorável, enquanto a Floresta Estacional Semidecidual, em torno de $30 \%$, formando, no fim da estação seca, um verdadeiro tapete de folhas secas. Geralmente, as áreas ocupadas, pela Floresta Estacional Semidecidual, apresentam-se em solos férteis e com relevância na economia regional. Entre as espécies encontradas pode-se citar Astronium fraxinifolium Schott (gonçalo), Lithraea molleoides (Vell.) Engl. (aroeirinha), Myracrodruon urundeuva (Engl.) Fr. All. (aroeira), Aspidosperma cylindrocarpon Muell. Arg. (peroba), A. subincanum Mart. (guatambu), Acrocomia aculeata (Jacq.) Lodd. (bocaiúva), Tabebuia impetiginosa (Mart.) Standl. (piúva-da-mata), Cordia glabrata (Mart.) A DC. (louro-preto), Combretum leprosum Mart. (carne-de-vaca), Cnidosculus cnicodendron Griseb. (cansanção), Acacia farnesiana Willd. (aromita), A. paniculata Willd. (espinheiro), entre outras (FURTADO et al., 1982; POTT; POTT, 2003).

As áreas de Floresta Estacional são caracterizadas pela presença de espécies como Anadenanthera collubrina (Vell) Brenan. (angico), Ceiba boliviana Britton \& Baker f. (barriguda), Combretum leprosum Mart. (carne-de-vaca) e Tabebuia impetiginosa (piúva-roxa) no dossel (FURTADO et al., 1982; POTT; POTT, 2003).

A Floresta Estacional Semidecidual Aluvial caracteriza-se por ser uma floresta ribeirinha, ocupando as acumulações fluviais quaternárias (FURTADO et al; 1982), com grande riqueza de espécies. Em uma área utilizada para turismo no rio da Prata, (DAMASCENO JÚNIOR et al., 2000) encontraram 101 espécies de plantas, com Inga heterophylla Willd, I. vera Willd e Ficus sp. formando o dossel e Piper angustifolium R. \& $P$. no sub-bosque das faixas mais úmidas. Nas áreas com menor influência da variação do lençol freático, em transição para floresta decídua, ocorrem Aspidosperma cylindrocarpum Muell. Arg, Tabebuia impetiginosa (Mart.) Standl., Holocalyx balansae Micheli e Nectandra membranacea (Sw.) Griseb. no dossel, e no sub-bosque, Unonopsis lindmanii Fries e Casearia cf. mariquitensis H.B.K.

Muitos rios da região apresentam uma grande biomassa de macrófitas aquáticas, que é formada principalmente por espécies submersas como Heteranthera reniformis Ruiz et. Pav., $H$. zosterifolia Mart. e Myriophyllum aquaticum (Vell.) Verd. além de outras espécies aquáticas flutuantes como Eleocharis geniculata (L.) R. \& S. e Bohemeria cylindrica (L.) Sw. (DAMASCENO-JÚNIOR et al; 2000). Ocorrem também ao longo dos rios, especialmente em alguns brejos da bacia do rio Formoso, que são caracterizados pela presença de cyperáceas como Rhynchospora cf. tenuis Link. e ainda arbustos como Erythrina speciosa Andr.
(SCREMIN-DIAS et al., 1999; DAMASCENO-JÚNIOR et al., 2000).

O Cerrado lato sensu é uma vegetação lenhosa de altura máxima de 15 metros, com casca grossa e rugosa, de aparência xeromórfica, com fisionomia diversificada e variações na composição florística, porém com algumas espécies que se repetem com bastante frequência (FURTADO et al., 1982; RIBEIRO; WALTER, 1998). Dentro desta formação encontra-se a vegetação conhecida como cerradão (Savana Florestada), caracterizando-se pelo agrupamento de espécies vegetais arbóreas, apresentando esgalhamento profuso e altura variando entre 8 a 15 metros e muito importante devido a presença de várias espécies de interesse econômico, como Atronium fraxinifolim Schott (gonçalo), Myracrodruon urundeuva (Engl.) Fr. All. (aroeira), Aspidosperma tomentosum Mart. (peroba-do-campo), Acrocomia aculeata (Jacq.) Lodd. (bocaiúva), Jacaranda cuspidifolia Mart. (caroba), Tabebuia aurea (Manso) B. \& H.) (ipê amarelo ou paratudo), Tabebuia impetiginosa (Mart.) Standl. (piúva-da-mata), Tabebuia ochracea (Cham.) Standl (piúva-cascuda) e Tabebuia roseo-alba (Ridl.) Sandw (ipê branco) (FURTADO et al., 1982).

No entanto, a classificação quanto ao tipo de vegetação é controversa e muitas vezes os limites ocorrem em gradientes e são poucos claros, além de existir também uma transição ou mistura entre diferentes formas vegetacionais (POTT; POTT, 2003).

Essa diversidade de fitofisionomias, aliadas a fragmentação causada pela ação antrópica desfigurou parte das paisagens originais da região, criando um complexo mosaico paisagístico, com porções de Cerrado e zonas de transição, por suas características florísticas e fisionômicas, alvo de ação antrópica mais intensa, devido à concepção errônea de aparente "pobreza" das espécies florestais, trocando a vegetação nativa por pastagens artificiais (DIAS, 2000).

Atualmente, a base econômica regional é a pecuária de corte praticada de forma extensiva, porém muitas vezes não apresentam tratos culturais específicos, ocasionando degradação do solo, principalmente erosão e compactação, além de queimadas e desmatamentos para estabelecimento das pastagens (BRASIL, 1997).

Outro fator que ameaça a região é a ação das carvoarias, que têm avançado muito rapidamente no Estado. Essa atividade está intimamente associada à pecuária, pois parte da supressão vegetal que se inicia com a derrubada através de correntes, presas aos tratores, arrancando a vegetação pela raiz sem distinção de espécies e tamanho, é resultado de parcerias entre fazendeiros, interessados em aumentar a área de pastagem e donos de carvoarias, que necessitam de madeira 
para viabilizar seus negócios (SILVA, 2001). Depois da derrubada de vegetação, as árvores de interesse são serradas e queimadas em fornos, originando o carvão vegetal. Além disso, a fiscalização precária associada à legislação falha e à falta de conscientização ambiental levaram a sérios problemas de degradação ambiental na região, tal como o assoreamento dos rios (HARRIS et al., 2006).

A produção de carvão vegetal em Mato Grosso do Sul, antes do ano de 1985, ocorria com o trabalho familiar, em pequenas unidades de produção, com a permanência do trabalhador nas propriedades rurais curta (de 3 a 5 meses), ocasionando um pequeno impacto ambiental. A partir de 1985, começaram a instalar-se no Estado, particularmente nos municípios de Ribas do Rio Pardo e Água Clara, as primeiras empresas produtoras de carvão, representadas tanto por empreiteiras, como por intermediários, os "gatos", ou ainda pelos arrendatários na sua maioria dos Estados de Minas Gerais e de São Paulo. Esta produção visa prioritariamente a demanda do setor siderúrgico brasileiro, para empresas instaladas nos Estados de Minas Gerais, Espírito Santo, Maranhão, Pará, Rio Grande do Norte e Mato Grosso do Sul (SILVA, 2001).

Outra ameaça importante à manutenção da riqueza de espécies na região são as queimadas, uma ameaça ao desenvolvimento sustentável. Os prejuízos diretos e indiretos que os incêndios causam com a destruição das florestas e matas, assim como os riscos decorrentes da eliminação de cobertura vegetal nas regiões vulneráveis, justificam plenamente qualquer esforço (LIU, 2007) para evitar ou diminuir a ação do fogo sobre os ecossistemas naturais.

Também nos últimos anos vários empreendimentos de mineração instalaram-se em alguns municípios da região (IBGE, 1998), com a consequente descaracterização da paisagem, incrementando processos erosivos devido a falta de cobertura vegetal, causando assoreamentos e modificando a trajetória dos corpos d'água, além de contaminar as bacias com dejetos de diferentes origens (DIAS, 2000; HARRIS et al., 2006).

Merece ser ressaltada a exploração de calcário como matéria prima para a construção civil, além da utilização na agricultura e nas pastagens. A sua exploração implica na abertura de clareiras na vegetação, desestruturando a vegetação e deixando áreas vazias na floresta depois de abandonadas as atividades (DIAS, 2000). Este tipo de atividade é de grande importância na região, devido ao tipo de rocha que forma a Serra da Bodoquena.

Estas ações antrópicas de diferentes formas levaram a uma descaracterização de parte das fitofisio- nomias da região da Serra da Bodoquena, onde áreas completamente desprovidas de vegetação natural convivem lado a lado com áreas intocadas ou parcialmente desmatadas, as primeiras áreas associadas aos vales aplainados e as segundas, aos mogotes (DIAS, 2000). Os grandes vales aplainados são os locais destinados ao cultivo de cereais, em especial a soja e o milho, além de pastagens artificiais visto a facilidade de mecanização; estas áreas têm aumentado consideravelmente nos últimos anos devido o avanço da fronteira agrícola de forma maciça, e à alta fertilidade dos solos que atraiu agricultores de forma rápida e intensiva para a região (DIAS, 2000; HARRIS et al., 2006).

Uma das atividades de menor impacto que vem adquirindo importância econômica nesta região é o turismo. A partir da década de 1980, o Estado passou a explorar melhor suas potencialidades turísticas, aproveitando-se da atração que a região pantaneira possui, além de outras áreas periféricas ao Pantanal, que passaram a atrair um grande fluxo de pessoas (PUTRICK et al., 2006).

A exploração do turismo em água doce, uma das principais características da Serra, consiste em um leque de possibilidades de desenvolvimento regional e local. Além dos aspectos bucólicos das paisagens, seu relevo peculiar propicia uma atividade geradora de receita e emprego, pois a beleza cênica revelada na região pelas formas criadas pelo processo de carstificação das rochas calcárias tem feito o turismo despertar como uma nova fonte de renda para a região, especialmente para o município de Bonito, o que pode implicar em outra ameaça ao equilíbrio ambiental e torna mais importante a coleta de dados relacionados às diferentes vertentes da questão ambiental, pois, segundo Dias (2000) e Rodrigues et al. (2004), a coleta de dados nestes ambientes pode responder as perguntas de caráter prático, relativas à sua conservação.

A atividade turística, quando mal conduzida, pode afetar negativamente os componentes sensíveis do ambiente, pois para a prática correta do ecoturismo, devem ser estabelecidos protocolos de visitação que visam minimizar o conflito entre recreação e conservação da natureza (SABINO; ANDRADE, 2003). Diante deste contexto, imagens de satélite podem ser importantes para avaliar o grau de impacto sofrido pelo ambiente, áreas de fragilidade e de interesse preservacionista, bem como ações para sua conservação e locais adequados para a atividade turística.

Levando-se em consideração a importância ecológica e econômica da região da Serra da Bodoquena, este trabalho tem por objetivo quantificar as áreas de vegetação nativa, de pastagens e de solo exposto entre diferentes períodos de tempo. 


\section{MATERIAL E MÉTODOS}

A área de estudo está representada na Figura 1, localizada nos municípios de Jardim, Porto Murtinho, Bonito e Bodoquena e situada no corte cartográfico (projeção Universal Transversa de Mercator - UTM) 465592,911E e 7567135,549N - limite inferior; e, $561084,499 \mathrm{E}$ e a $7806856,349 \mathrm{~N}$ limite superior, em que se localiza a Serra da Bodoquena, e outras pequenas elevações, separadas do grande maciço da Bodoquena, mas que foram consideradas como participantes dessa mesma unidade por apresentar as mesmas características fisionômicas.

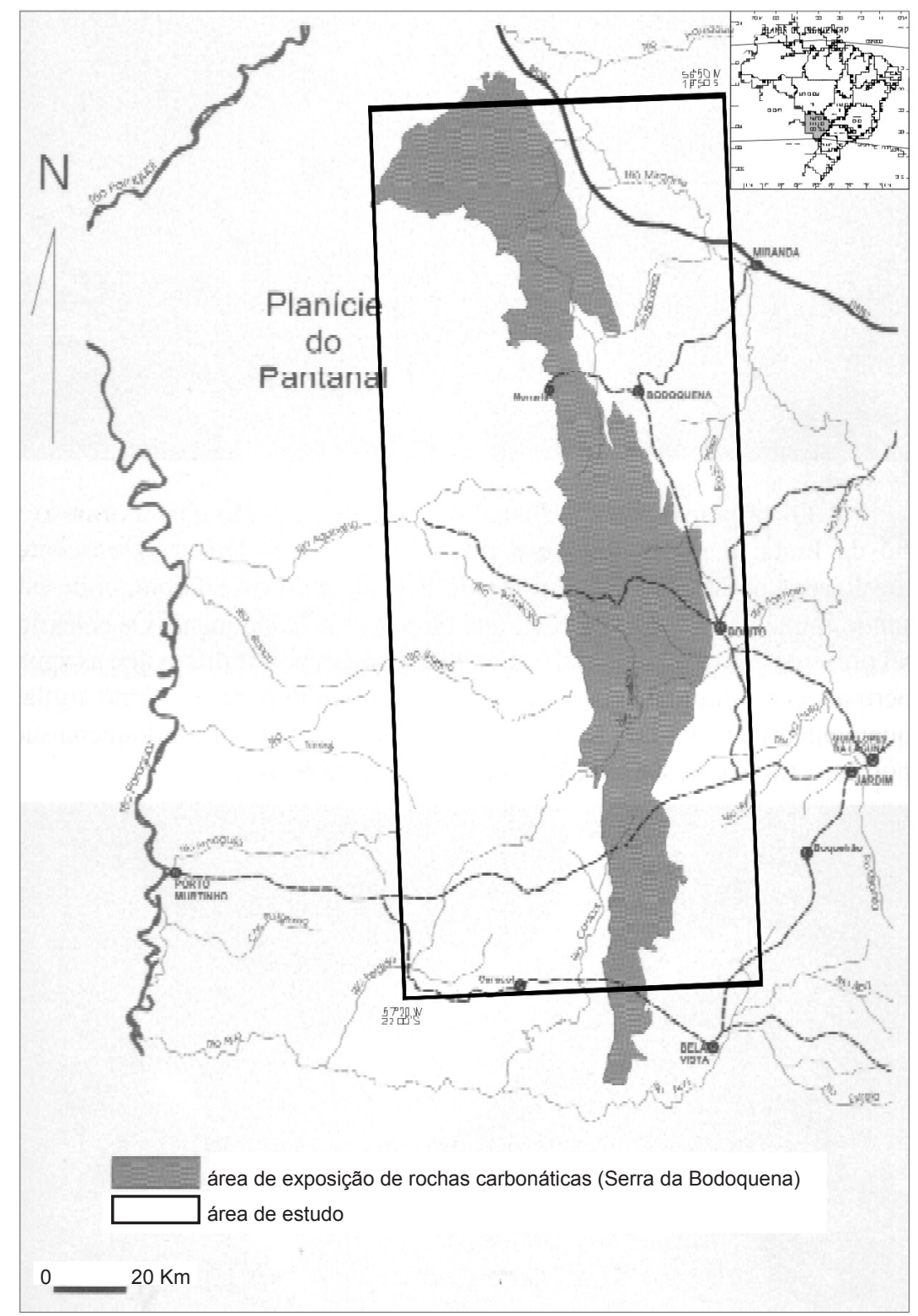

FIGURA 1 - ÁREA DA SERRA DA BODOQUENA, MATO GROSSO DO SUL, BRASIL (BOGGIANI, 1999) E DELIMITAÇÃO DAREGIÃO ESTUDADA. Org.: Valtecir Fernandes e Celso Ramão Bernardes dos Santos, (2008) 
OLIVEIRA, A. K. M. et al. Avaliação da perda da vegetação arbórea nativa...

Foram adquiridas imagens dos Satélites LANDSAT 2 e 5 dos anos de 1979, 1993, 2000 e 2007 e Cartas Topográficas (1966). Também realizadas visitas a campo para a verificação de pontos de vegetação.

As cenas usadas de 1979 foram as do satélite LANDSAT 2, órbita 243 ponto $74 \mathrm{com}$ passagem do satélite em 25 de setembro de 1979 , órbita 242 ponto 74 com passagem do satélite em 25 de setembro de 1979, órbita 243 ponto 75 com passagem do satélite em 21 de agosto de 1979, órbita 242 ponto $75 \mathrm{com}$ passagem do satélite em 25 de setembro de 1979 Multi Spectral System (MSS), e as cenas usadas do ano de 1993 do satélite LANDSAT 5: órbita 226 ponto $74 \mathrm{com}$ passagem do satélite em 22 de maio de 1993, órbita 226 ponto 75 com passagem do satélite em 23 de junho de 1993 (INPE, 2008).

As cenas dos anos de 2000 e 2007 são LANDSAT 5. As cenas do ano de 2000 são as da órbita 226 ponto 74 com passagem do satélite em 23 de abril do ano de 2000 e a órbita 226 ponto 75 com passagem do satélite em 23 de abril do ano de 2000. As imagens do ano de 2007 são as da órbita 226 ponto 74 com passagem do satélite em 26 de março do ano de 2007 e a da órbita 226 ponto 75 com passagem do satélite em 26 de abril do ano de 2007 (INPE, 2008).

As cartas topográficas foram da Diretoria de Serviço Geográfico do Exército (DSG). Folha SE-21-YD-VI MI-2508 Porto Esperança do ano de 1966, Folha SE-21-Z-C-IV MI-2509 Barranco Vermelho do ano de 1966, Folha SE-21-Z-C-V MI-2510 Porto Ciriáco do ano de 1966, Folha SF-21-V-B-III MI-2546 Morro Pantanal do ano de 1966, Folha SF-21-X-A-I MI-2547 Coronel Juvêncio do ano de 1965, Folha SF 21-X-A-II MI-2548 Miranda do ano de 1966, Folha SF-21-V-B-VI MI-2582 Aldeia Tómazia do ano de 1966, Folha SF-21-X-A-IV MI-2583 Vila Campão do ano de 1966, Folha SF-21X-A-V Ml-2584 Aldeia Lalíma do ano de 1966, Folha SF-21-V-D-III MI-2618 Fazenda Santa Otilia do ano de 1966, Folha SF-21-X-C-I Ml-2619 Rio Perdido do ano de 1966, Folha SF-21-X-C-II MI-2620 Jardim do ano de 1966, Folha SF-21-V-D-VI MI-2653 Colônia São Lourenço do ano de 1966, Folha SF-21-X-C-IV MI-2654 Fazenda Margarida do ano de 1966, Folha SF-21-X-C-V MI-2655 Boqueirão do ano de 1966 (MINISTÉRIO DO EXÉRCITO, 1966), sendo as mesmas mosaicadas no SPRING 4.2 e depois digitalizadas no Software Autocad Map 2000.

As imagens LANDSAT 2 e 5 referente aos anos de 1979, 1993, 2000 e 2007 foram combinadas nas composições R G B no Software Corel Photo Paint 12. Foram escolhidas as composições: bandas $4 R 7 G$ $5 B$ para as imagens LANDSAT 2 e $3 R$ $4 G$ 2B para as imagens LANDSAT 5. Posteriormente as imagens foram recortadas nas bordas para eliminação de ruídos que surgiam na formação dos mosaicos. Este procedimento fez perder a formatação original georreferenciada (geotif) e então as imagens foram transformadas para o formato GRIB no módulo Impima do SPRING 4.2. Com auxilio do Software do Google Earth 4.0 foram adquiridos os pontos de controle e as mesmas foram registradas no software SPRING 4.2.

O mosaico das cartas topográficas foram georreferenciadas no Auto Cad Map com a ferramenta Rubber Sheet, na sequência foram digitalizadas e posteriormente passadas para o formato matricial e os polígonos vetorizados de acordo com as classes contidas nas legendas das cartas, sendo: (1) Floresta Estacional Decidual Submontana e Floresta Estacional Semidecidual; (2) Cerrado Lato Sensu; (3) pastagem e culturas; e, Solo Exposto e Pastagens Degradadas, definidas conforme os objetivos do trabalho, permitindo separar, identificar e quantificar a área de cada classe no SPRING 4.2.

A classificação usada no SPRING 4.2 foi o método da distância euclidiana, por ter apresentado menores percentuais na matriz de confusão, estando de acordo com experiências de Garnés (2004) e Salles et al. (2005) realizadas, respectivamente, na sub-região do Pantanal do Negro e no Parque Estadual do Rio Ivinhema.

\section{RESULTADOS E DISCUSSÃO}

Os trabalhos referentes a Serra da Bodoquena normalmente não quantificam o tamanho que este maciço ocupa. Levando-se em consideração as características fisionômicas da região, pode-se afirmar que esta formação possui uma área de 2.289.181,77ha, cuja cobertura vegetal existente foi classificada.

Ocorreram diferenças entre as áreas ocupadas por distintas classes de vegetação entre os anos de 1966 e 1979. De acordo com Pott e Pott (2003), muitas vezes os limites entre diferentes formas vegetacionais ocorrem em gradientes e são poucos claros, o que foi verificado nas classificações e seus resultados, dificultando a correta separação das diferentes formas vegetacionais, principalmente em relação às imagens mais antigas (1966 e 1979), que possuem menor resolução.

Desta maneira, o mosaico das cartas de 1966 (Figura 2) classifica parte da Savana Florestada como Floresta Semidecidual Submontana e em 1979, a 
Floresta Semidecidual Submontana como Savana Florestada, o que volta a ocorrer em 1993. As imagens de 2000 e 2007 (Figura 3), de melhor resolução, podem

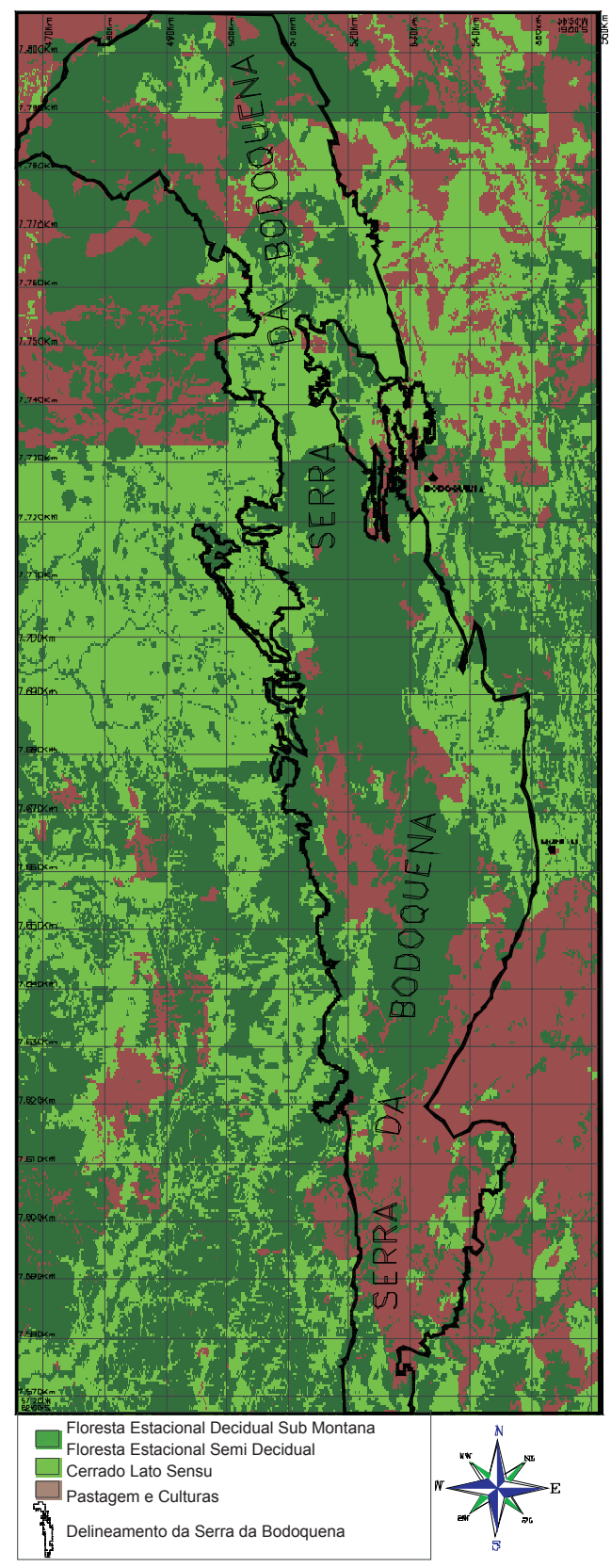

FIGURA 2 - CLASSIFICAÇÃO DAS CARTAS TOPOGRÁFICAS DE 1966 DA SERRA DA BODOQUENA, MATO GROSSO DO SUL, BRASIL, ATRAVÉS DO MÉTODO DA DISTÂNCIA EUCLIDIANA (Escala 1:670.000 - Org.: Silvio Jacks dos Anjos Garnés e Celso Ramão Bernardes dos Santos, 2008) ser consideradas mais exatas.

Para evitar que a interpretação errada das imagens causa-se um erro sobre a proporção da vegetação

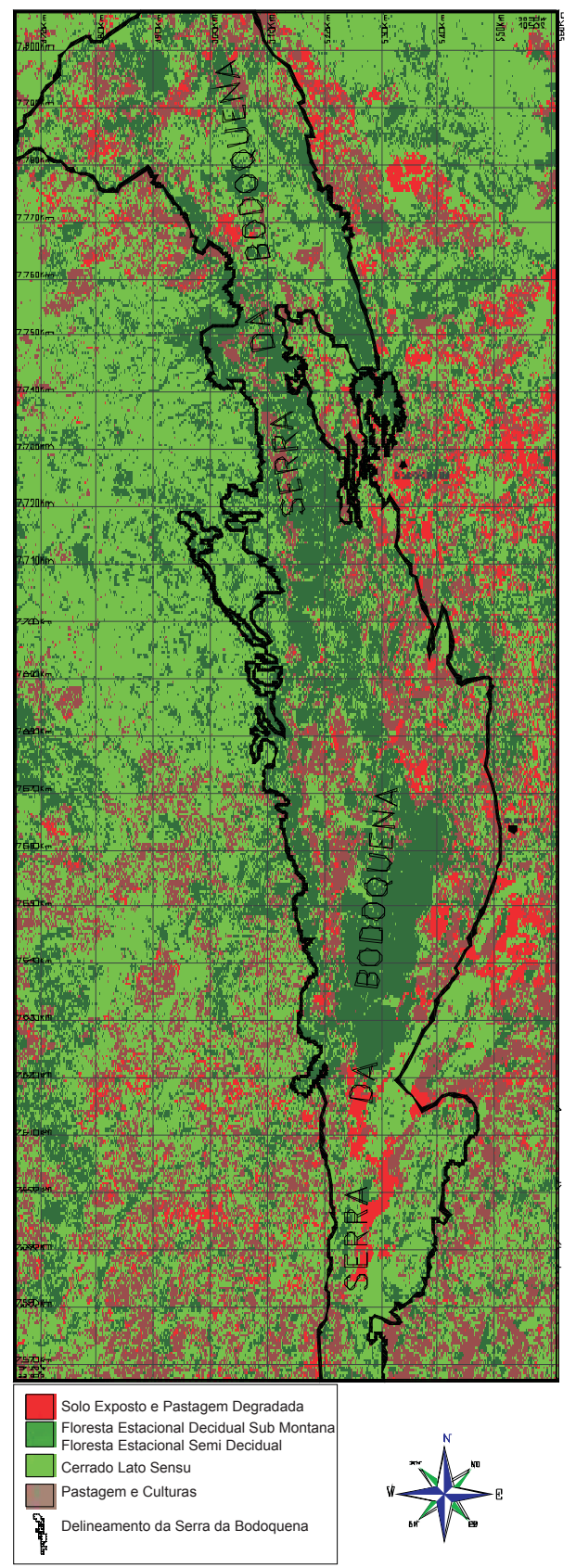

FIGURA 3 - CLASSIFICAÇÃO DAS IMAGENS DE SATÉLITE LAND SAT 5, ÓRBITA 226 DO ANO DE 2007 ATRAVÉS DO MÉTODO DA DISTÂNCIAEUCLIDIANA, SERRADABODOQUENA, MATO GROSSO DO SUL, BRASIL (Escala 1:670.000 - Org.: Silvio Jacks dos Anjos Garnés e Celso Ramão Bernardes dos Santos, 2008) 
arbórea presente na área, estas duas classes vegetacionais foram unidas, considerando-se a partir de 1979 como o total de vegetação arbórea, 1.916.992,80ha. O valor total encontrado em 1966 (1.799.091,63ha) provavelmente foi subestimado na restituição fotogramétrica que geraram as cartas topográficas, devido ao tipo de procedimento adotado.
Assim, levando-se em consideração o valor do ano de 1979 (1.916.992,80 ha) e 2007 (1.683.797,40 ha), ocorreu uma diminuição de $233.195,4$ ha de vegetação arbórea na região, equivalendo a 10,19\% da área (Tabela 1).

TABELA 1 - CLASSIFICAÇÃO DAS ÁREAS NATURAIS DE VEGETAÇÃO ARBÓREA NATIVA DA SERRA DA BODOQUENA - MS, PELO MÉTODO DA DISTÂNCIA EUCLIDIANA (ORG.: Valtecir Fernandes, 2008)

\begin{tabular}{|c|c|c|c|c|c|}
\hline CLASSES & 1966 & 1979 & 1993 & 2000 & 2007 \\
\hline $\begin{array}{l}\text { Florestas } \\
\text { Decidual } \\
\text { Submontana e } \\
\text { Semidecidual }\end{array}$ & $1.005 .362,91$ & $473.803,56$ & $711.476,46$ & $748.631,70$ & $548.554,41$ \\
\hline $\begin{array}{l}\text { Cerrado Lato } \\
\text { Sensu }\end{array}$ & $793.728,72$ & $1.443 .189,24$ & $1.105 .103,70$ & $986.768,37$ & $1.135 .242,99$ \\
\hline Total de áreas & $1.799 .091,63$ & $1.916 .992,80$ & $1.816 .580,16$ & $1.735 .400,07$ & $1.683 .797,40$ \\
\hline
\end{tabular}

Pode-se também observar que existe uma tendência a diminuição no processo de perda da vegetação nativa. O período compreendido entre 1979 e 1993 (14 anos) teve uma perda de 100.412,64 ha. Entre 1993 e 2000 (7 anos) ocorreu uma diminuição de 81.180,09 ha e no intervalo de 2000 e 2007 (7 anos), 51.602,67 ha. Apesar do recuo contínuo na área desmatada, os valores encontrados continuam altos, levando-se em consideração que o local é uma região de planalto, com inclinação maior que $45^{\circ}$, teoricamente protegidas por lei (Áreas de Preservação Permanente).

O maior período de perda foi de 1979 até o ano de 1993, devido ao tempo avaliado (14 anos); porém quando se analisa metade deste ciclo, o resultado é uma perda de 50.206,32 hectares de mata nativa a cada sete anos, indicando que as perdas, a cada etapa de sete anos, situam-se entre 50 e 81 mil hectares. Levandose em consideração o tamanho do Parque Nacional da Serra da Bodoquena (77.232 ha), situado na Serra da
Bodoquena, ocorre uma perda média de um parque a cada período de tempo avaliado (7 anos).

As Áreas Antropizadas também apresentaram um aumento de área. Levando-se em consideração os valores encontrados em 1966 (490.090,14 ha) e os de 2007 (605.384,37 ha), pode-se afirmar que ocorreu um aumento de 115.294,23 ha (Tabela 2), o que confirma a redução nas áreas de vegetação nativa.

O valor encontrado para o ano de 1966 provavelmente está superestimado, resultado da leitura incorreta das imagens devido à baixa resolução destas. No ano de 1993 ocorreu uma diminuição nos valores encontrados para a Classe Solo Exposto e Pastagens Degradadas, porém com novo aumento a partir de 2000. Neste caso também talvez tenha ocorrido uma leitura errada entre as duas classes estudadas, já que tendência é um aumento gradativo nas áreas de solo exposto e pastagens degradadas.

TABELA 2 - CLASSIFICAÇÃO DAS ÁREAS ANTROPIZADAS NA SERRA DA BODOQUENA - MS, PELO MÉTODO DA DISTÂNCIA EUCLIDIANA (SUPERVISIONADO) Org.: Valtecir Fernandes (2008)

\begin{tabular}{|c|c|c|c|c|c|}
\hline CLASSES & 1966 & 1979 & 1993 & 2000 & 2007 \\
\hline $\begin{array}{l}\text { Pastagem e } \\
\text { Culturas }\end{array}$ & $490.090,14$ & $263.793,96$ & $375.473,88$ & $430.109,01$ & $478.249,83$ \\
\hline $\begin{array}{l}\text { Solo Exposto e } \\
\text { Pastagens Degra- } \\
\text { dadas }\end{array}$ & ---------------- & $108.395,01$ & $97.127,73$ & $123.672,69$ & $127.134,54$ \\
\hline Total de áreas & $490.090,14$ & $372.188,97$ & $472.601,61$ & $553.781,7$ & $605.384,37$ \\
\hline
\end{tabular}


A partir do ano de 1979 pode-se verificar um aumento gradativo nas áreas antropizadas, com o período compreendido entre 1979 e 1993 (14 anos) apresentando um crescimento de 100.412,64 ha. Entre os anos de 1993 e 2000 (7 anos), 81.180,09 ha e no período de 2000 a 2007 (7 anos), 51.602,67 ha, o que confirma os dados da tabela 1 , onde verificou-se uma diminuição na velocidade de antropização da área, apesar dos valores ainda altos.

O aumento contínuo nas áreas de solo exposto e pastagens degradadas são preocupantes, pois ocorre em locais com declividade que propiciam processos erosivos e assoreamento de rios e córregos, além de diminuir os processos de recarga do Aquífero na região, importante reserva de água.

A implantação do Parque Nacional da Serra da Bodoquena, criado em setembro de 2000 , porém com a situação fundiária ainda não regularizada, foi uma maneira de diminuir o avanço da degradação ambiental na região, porém a maior parte da Serra (2.211.949,77 ha) continua sem uma proteção efetiva, pois apesar da Legislação Ambiental proteger morros e encostas com declividade superior a $45^{\circ}$ graus, as queimadas e desmatamentos para a formação de carvão vegetal são consistentes.

Harris et al. (2006) coloca que a cobertura original suprimida nos Planaltos que cercam o Pantanal, da qual a Serra de Bodoquena faz parte, foi de $63 \%$ de sua extensão total. Este valor, bem acima dos encontrados por este trabalho, indica que a região ainda apresenta uma vegetação bem conservada, em relação a outros planaltos, que formam a Bacia do Alto Paraguai, principalmente devido à dificuldade de acesso a algumas partes da região. Porém os mesmos autores colocam que o município de Bodoquena é um dos que apresentam as taxas mais altas de desmatamento, com 40 a $60 \%$ de sua vegetação original suprimida, e com tendência de aumento nestes valores devido às licenças de desmatamento concedidas. Este padrão parece indicar que o processo de modificação na vegetação nativa tende a se intensificar nos próximos anos, aumentando as áreas antropizadas.

\section{CONCLUSÃO}

A metodologia aplicada permitiu verificar a diminuição da vegetação nativa arbórea na região, com um decréscimo de $233.195,4$ ha, cerca $10,19 \%$ de 2.289.181,77 ha, em 28 anos. Embora seja conhecida a deficiência de qualquer algoritmo em termos de classificação digital, os percentuais obtidos das análises multitemporais com períodos superiores a 10 anos exprimem bem o aumento do uso e ocupação do solo na região, levando a uma reflexão sobre a atual política de desenvolvimento, que deveria buscar a conservação em vez da supressão.

\section{AGRADECIMENTOS}

À FUNDECT, pela bolsa concedida.

\section{REFERÊNCIAS}

ALVARENGA, S. M.; BRASIL, A. E.; DEL' ARCO, D. M. Geomorfologia. In: BRASIL. Ministério das Minas e Energia. Projeto Radam Brasil, Levantamento de recursos naturais, Folha SF. 21 Campo Grande. Rio de Janeiro: Divisão de publicação, 1982, v. 28. p. 125-148.

BATARCE, A. P. A.; MORETTI, E. C. Criação do Parque Nacional da Serra da Bodoquena. Disponível em: <http:/l www.igeo.uerj.br/VICBG-2004/Eixo2/E2-054.htm>. Acesso em 24/09/2006.

BRASIL. Ministério do Meio Ambiente, dos Recursos Hídricos e da Amazônia Legal. Plano de Conservação da Bacia do Alto Paraguai - PCBAP / Projeto Pantanal. Brasília: Programa Nacional de Meio Ambiente, PNMA, 1997, v. 3, p. 50-60.

BOGGIANI, P. C. Geologia da Bodoquena. In: SCREMINDIAS, E. S.; POTT, V. J.; HORA, R. C.; SOUZA, P. R. Nos jardins submersos da Bodoquena. Campo Grande: UFMS, 1999. p. 10-23.

DAMASCENO-JUNIOR, G. A.; NAKAJIMA, J. N.; RESENDE, U. M. A floristic survey of the Rio Negro, Rio Aquidauana and Rio Miranda watersheds (Headwaters) of the Pantanal, Mato Grosso do Sul, Brasil. In: WILLINK, P. W.; CHERNOFF, B.; ALONSO, L. E.; MONTAMBAULT, J. R. (Eds.). A biological assessment of the aquatic ecosystems of the Pantanal, Mato Grosso do Sul, Brasil. Bulletin of Biological Assessment 18. Washington, DC Conservation International. 2000.

DIAS, J. A região cárstica de Bonito, M.S.: uma proposta de zoneamento geoecológico à partir de unidades de paisagem. Ciência Geográfica, v. 1, p. 14-24, 2000.

FURTADO, P. P.; GUIMARÃES, J. G.; FONZAR, B. C. Vegetação. In: BRASIL. Ministério das Minas e Energia. Projeto Radam Brasil, Levantamento de recursos naturais, Folha SF. 21 Campo Grande. Rio de Janeiro: Divisão de publicação, 1982, v. 28, p. 281- 327.

GARNÉS, S. J. A. Implementação computacional de classificadores digitais: aplicação na caracterização de 
ambientes pantaneiros. In: Simpósio de Ciências Geodésicas e Tecnologias da Geoinformação, 1., 2004, Recife, Anais...

HARRIS, M. B.; ARCÂNJO, C.; PINTO, E. C. T.; CAMARGO, G.; NETO, M. B. R.; SILVA, S. M. Estimativa da perda de cobertura vegetal original na Bacia do Alto Paraguai e Pantanal brasileiro: ameaças e perspectivas. Revista Natureza \& Conservação, v. 4, n. 2, p. 50-66, 2006.

IBGE. Instituto Brasileiro de Geografia e Estatística. Censo Agropecuário 1995-1996. n. 24. Mato Grosso. Rio de Janeiro. 231p. 1998.

INPE. Instituto Nacional de Pesquisas Espaciais. São José dos Campos. Imagem LANDSAT 2 e 5. Disponível em: <http:// www.dgi.inpe.br/CDSR/manage.php?INDICE.htm>. Acesso em: 08/04/2008.

LIU, W. T. H. Aplicações de sensoriamento remoto. Campo Grande: UNIDERP, 2007, p. 535-557. 908p.

MINISTÉRIO DO EXÉRCITO, 1966. Diretoria de Serviço Geográfico do Exército - DSG. Cartas topográficas: Porto Esperança, 1966. Folha SE - 21-Y-D-VI MI-2508; Barranco Vermelho, 1966. Folha SF-21-Z-C-I. Ml-2509; Porto Ciriáco, 1966. Folha SE-21-Z-C-V Ml-2510; Morro Pantanal, 1966. Folha SF-21-V-B-III MI-2546; Coronel Juvêncio, 1964. Folha SF-21-X-A-I MI-2547; Miranda, 1966. Folha SF-21-X-A-II MI2545; Aldeia Tómazia, 1966. Folha SF-21-V-B-VI MI-2582; Vila Campão, 1966. Folha SF-21-X-A-IV MI-2583; Aldeia Lalíma, 1966. Folha FS-21-X-A-V Ml-2584; Fazenda Santa Otilia, 1966. Folha SF-21-V-D-III MI-2618; Rio Perdido, 1966. Folha SF-21-X-C-I MI-2619; Jardim, 1966. Folha SF-21-X-C-II MI-2620; Colônia São Lourenço, 1966. Folha SF-21-V-D-VI MI-2653; Fazenda Margarida, 1966. Folha SF-21-C-IV MI2654; Boqueirão, 1966. Folha SF-21-C-V MI-2655. Escala 1:100.000.

PONZONI, F. J. Comportamento espectral da vegetação. In: MENESES, P. R.; NETTO, J. S. M. Sensoriamento remoto: reflectância dos alvos naturais. Brasília: UnB, 2001. p. 155199.

POTT, A.; POTT, V. J. Espécies de fragmentos florestais em Mato Grosso do Sul. In: COSTA. R. B. D. Fragmentação florestal e alternativas de desenvolvimento rural na região centro oeste. Campo Grande: UCDB, 2003. p. 26-52.

PUTRICK, S. C.; OLIVEIRA, A. K. M.; GARNÉS, S. J. A.; MERCANTE, M. A.; NOGUEIRA, A. X. O impacto do uso e ocupação desordenado do solo sobre atividade turística no Balneário Lagoa Rica - Campo Grande. In: BRUM, E.; OLIVEIRA, A. K. M.; FAVERO, S. (Org.). Meio Ambiente e Produção Interdisciplinar: Sociedade, Natureza e Desenvolvimento. 1 ed. Campo Grande: UNIDERP, 2006, v. 1 , p. $229-242$

RIBEIRO, J. F.; WALTER, B. M. T. Fitofisionomias do bioma Cerrado. In: SANO, S. M.; ALMEIDA, S. P. Cerrado: ambiente e flora. Planaltina: Embrapa-CPAC,1998. p. 89-152.

RODRIGUES, E.; CAÍNZOS, R. L. P.; QUEÍROGA, J.; HERRMANN, B. C. Conservação em paisagens fragmentadas. In: CULLEN JR, L.; RUDRAN, R.; PADUA, C. V. Métodos de estudos em biologia da conservação \& manejo da vida silvestre. Curitiba: UFPR, p. 481-511, 2004.

SABINO, J; ANDRADE; L. P. Uso e Conservação da ictiofauna no ecoturismo da Região de Bonito, Mato Grosso do Sul: o mito da sustentabilidade ecológica no Rio Baía Bonita (Aquário Natural de Bonito). Revista Biota Neotropica, v. 3, n. 2, p. 1-9, 2003.

SALLES, F. M; BONONI, V. L. R.; GARNÉS, S. J. A.; SABINO, J.; PARANHOS FILHO, A. C. Análise multitemporal da dinâmica de ocupação do solo da região do Parque Estadual das Várzeas do rio Ivinhema, Mato Grosso do Sul. Revista de Estudos Ambientais, v. 7, n. 2, p. 12-19, 2005.

SCHAEFFER, R. O.; OLIVEIRA, A. K. M.; FAVERO, S.; SOUZA, C. C. Gestão florestal em Mato Grosso do Sul. In: BAUER, F C.; VARGAS JUNIOR, F M. Produção e gestão agroindustrial. Campo Grande: UNIDERP, 2005. p. 63-80.

SCREMIN-DIAS, E.; POTT, V. J.; HORA, R. C.; SOUZA, P. R. Nos jardins submersos da Bodoquena: guia para identificação de plantas aquáticas de Bonito e região. Campo Grande: UFMS, 1999. 160p.

SILVA, E. A. O processo produtivo do carvão vegetal: um estudo em Mato Grosso do Sul. 307p. Tese (Doutorado em Desenvolvimento Regional) - Universidade Estadual Paulista, 2001. 